\title{
Espaço autônomo e papel próprio: representações de enfermeiros no contexto do binômio saúde coletiva-hospital
}

\author{
Autonomous space and own role: nurses' representation in colective health-hospital context \\ Espacio autónomo y rol propio: representaciones de enfermeros en el contexto de la salud colectiva-hospital
}

\section{Antonio Marcos Tosoli Gomes', Denize Cristina de Oliveira'}

'Universidade do Estado do Rio de Janeiro, Faculdade de Enfermagem. Rio de Janeiro, RJ

Submissão: 13/02/2007

Aprovação: 24/08/2007

\section{RESUMO}

Este estudo objetiva analisar a estrutura da representação social da autonomia profissional. Trata-se de uma pesquisa Qualitativa com base nas Representações Sociais e desenvolvida com 83 enfermeiros de um município do Estado do Rio de Janeiro. Como coleta de dados utilizou-se a tarefa de evocação livre às expressões autonomia profissional e enfermagem e, para análise, recorreu-se ao Software EVOC. O núcleo da representação à expressão autonomia é constituído por conhecimento, con̨uista e responsabilidade, ao passo Que no termo enfermagem observa-se amor e dedicação. Percebe-se a presença de dimensões representacionais ligadas à pessoa dos profissionais e aos seus sentimentos. Conclui-se que as estruturas representacionais expostas demonstram um processo de conquista da autonomia profissional.

Descritores: Autonomia profissional; Papel profissional; Psicologia Social

\section{ABSTRACT}

This study has the objective of analzying the social representation structure of professional authonomy. It is a Qualitative research based on Social Representations and developed with 83 nurses in a city of Rio de Janeiro State, Brazil. In order to collect data it was used free evocation to expressions like professional authonomy and nursing and to analyse them EVOC software was used. The nucleous of representation to authonomy expression is build by knowledge, achievement and responsibility, whereas in nursing expression it is possible to observe love and dedication. It can be notice the presence of representational dimensions connected to the person of the professionals and to their feelings. It can be concluded that exposed representational structures show an achievement process of professional authonomy.

Descriptors: Professional authonomy, Professional role, Social psichology

\section{RESUMEN}

Este estudio tiene el objetivo de analisar la estructura de la representación social de la autonomía profesional. Es una busca calitativa basada en las representaciones sociales y desarrollada con 83 enfermeros de una cidad del Estado de Rio de Janeiro, Brasil. En la recogida de datos fue usada la tarea de evocación libre a las expresiones autonomía profesional y oficio de enfermera y, para el análisis, se usó el software EVOC. El núcleo de la representación a la expresión autonomía se compone de conocimiento, conQuista y responsablidad , además en la expresión enfermería se encuentra amor y dedicación. Se percibe presente las dimenciones representativas relacionadas a los profesionales y a sus sentimientos. Se concluye que las estructuras representacionales presentadas demostran un proceso de conQuista de la autonomía profesional.

Descritores: Autonomía profesional, Papel profesional, Psicología social. 


\section{INTRODUÇÃO/OBJETIVOS}

A enfermagem vive, nesses últimos tempos, conflitos históricos e momentos desafiadores. Os conflitos históricos possuem suas raízes no cuidar realizado primordialmente pela família e, mais especificamente, pela mãe, como forma direta de manutenção da vida individual e coletiva e perpassa os diversos momentos históricos definidores dos paradigmas de nossa civilização ${ }^{(1)}$. O início da era cristã, por exemplo, instala uma nova concepção de cuidados na profissão Que nega a interrelação corpo-espírito, dando supremacia ao espírito e conferindo ao corpo um status inferior. A enfermagem é, então, exercida por mulheres consagradas Que adotavam a submissão às ordens como atitude de valor e objetivavam mais à salvação da alma do Que à cura do corpo ${ }^{(2)}$.

A partir do século passado, surgem na enfermagem diversas teorias Que conferem um rosto intelectual à profissão. Contudo, apesar dessas teorias conferirem um arcabouço interno de sustentação à enfermagem, não a insere numa relação de mercado, nem mostra sua praticidade como sendo imprescindível à sociedade. Essas teorias conceituam o homem num nível de generalização muito grande, tornando-o abstrato e a-histórico, ao mesmo tempo em Que não consideram as contradições do processo de trabalho na enfermagem, tornando-se, portanto, acríticas ${ }^{(3)}$.

Outros aspectos importantes para a temática abordada são o processo de formação do enfermeiro e o modo como estes se relacionam com o poder. Determinados autores ${ }^{(4)}$ comentam acerca do processo de "docilização" a Que o estudante é submetido e ressalta a falta de uma análise crítica, durante a formação, acerca dos valores da profissão. Ainda destaca a dominação do corpo do estudante/enfermeiro através da normalização, do controle minucioso do tempo, da padronização das ações e técnicas, do perfeccionismo e do olhar hierárquico. Como conseqüência, os profissionais estão sempre controlando a assiduidade, a pontualidade, a lentidão na execução das tarefas de sua equipe e estabelecem um modo de relacionamento com a equipe de saúde Que gera mais sujeição Que modos criativos de resolução de conflitos.

Um último aspecto da problemática a ser destacado refere-se ao conflito histórico existente na profissão, ou seja, o eixo científico no Qual a enfermagem se insere. A prática de enfermagem é exercida, em sua maioria, no âmbito hospitalar e possui suas bases racionais na biologia, na medicina e na estatística.

Por isso, a profissão se apropria de conhecimentos científicos, objetivos e Quantitativos a fim de produzir uma atividade específica numa determinada instituição e contexto e o uso efetivo dessas áreas de conhecimento possibilitou a execução de procedimentos cada vez mais complexos no seu dia-a-dia. A enfermagem se encontra, portanto, integrada às ciências biomédicas e a problemática se estabelece entre essa ciência e as bases teóricas da profissão, Que se alimentam também, e principalmente, das ciências sociais e humanas. Por conseguinte, o cotidiano do profissional sobrevive à tensão entre o biológico e o social, o biomédico e as ciências sociais e humanas ${ }^{(5)}$.

Por outro lado, a enfermagem enfrenta os desafios Que a atualidade impõe. Tanto a Classificação Internacional da Prática de Enfermagem (CIPE) proposta pelo Conselho Internacional dos Enfermeiros (ICN) Quanto o desenvolvimento da consulta de enfermagem dentro dos Programas Básicos de Assistência à Saúde na rede básica, propõem modelos diferenciados de ações/ estratégias para os profissionais enfermeiros.

Em seu trabalho dentro da programação em saúde, o enfermeiro tem encontrado um amplo espaço de desenvolvimento para sua atuação diária. Este espaço se concretiza tanto no âmbito da consulta de enfermagem através do atendimento direto à clientela, com o suporte dos exames laboratoriais de rotina e da prescrição medicamentosa padronizada, ou através da educação em saúde, desenvolvida em nível individual ou na comunidade onde o profissional está inserido.

Em vista disto, objetiva-se, neste trabalho, analisar a estrutura da representação social da autonomia profissional da enfermagem a partir dos termos indutores "autonomia profissional" e "enfermagem".

\section{METODOLOGIA}

O estudo foi desenvolvido segundo a Teoria das Representações Sociais ${ }^{(6)}$ no âmbito da psicologia social, utilizando, inclusive, uma proposta teórica complementar, Qual seja, a abordagem estrutural ou a teoria do núcleo central ${ }^{(7-8)}$.

A representação é constituída por um conjunto de crenças, informações, opiniões e atitudes a propósito de um dado objeto social. Este conjunto de elementos se organiza, estrutura e se constitui em um sistema sociocognitivo de tipo específico ${ }^{(7)}$. Neste sentido, a organização de uma representação social apresenta uma característica específica, a de ser organizada em torno de um núcleo central, constituindo-se em um ou mais elementos Que dão significado à representação.

Esta teoria complementar propõe, então, a organização das representações sociais ao redor de seu núcleo central, sendo este o elemento que subsidia seu sentido fundamental e inflexível. Neste sentido, como característica ontológica de um núcleo central de determinada representação, ressalta-se a natureza do objeto representado, o tipo de relações Que o grupo mantém com este objeto e o sistema de valores e padrões sociais Que constituem o ambiente de vida, em sua dimensão objetiva e subjetiva, do indivíduo e do grupo.

Foram definidos, como sujeitos, 83 enfermeiros que trabalham em uma cidade do interior do estado do Rio de Janeiro. Desses, 42 desenvolvem suas atividades no contexto da atenção básica à saúde e 4 I na rede hospitalar do município. Dos profissionais compreendidos na rede básica, 30 desenvolvem suas atividades no atendimento direto à clientela, definido neste trabalho como sendo a realização da consulta de enfermagem, e os outros 12 ocupam cargos diversos na estrutura gerencial da saúde coletiva do município em Questão.

Foram selecionadas três instituições hospitalares para a realização do estudo com os enfermeiros Que atuam neste contexto. Com relação às mesmas, duas são públicas e uma particular de cunho filantrópico. Dos públicos, um é definido como sendo um hospital de grande porte, geral, de referência para toda a localidade e se situando em um dos distritos da cidade; o outro se localiza no centro da cidade e restringe suas atividades aos tratamentos clínicos, tanto de urgência Quanto de unidades intensivistas. O hospital particular-filantrópico é de grande porte, tendo enfermeiros em diversas funções gerenciais e assistenciais, sendo este, o primeiro 
hospital a ser fundado na cidade.

Considerando as propriedades Qualitativas e Quantitativas na determinação dos elementos centrais e periféricos de uma representação, empregou-se a técnica de evocação ou associação livre para a coleta de dados, utilizando-se como termos indutores as expressões autonomia profissional e enfermagem. A aplicação da técnica consistiu em solicitar aos sujeitos Que falassem cinco palavras ou expressões Que lhes ocorriam imediatamente à cabeça em relação ao termo referido.

Essa técnica de coleta de dados permite colocar em evidência o universo semântico do objeto estudado, assim como a sua dimensão imagética de forma mais rápida e dinâmica Que outros métodos com igual objetivo como, por exemplo, a entrevista ${ }^{(9-10)}$.

O produto das evocações foi organizado previamente, constituindo-se em um corpus para análise. O material foi, então, tratado pelo software EVOC 2000 Que calculou, para o conjunto do corpus, a freeüência simples de cada palavra evocada, as ordens médias de evocação de cada palavra e a média das ordens médias de evocação.

Os dados foram analisados a partir de sua distribuição no "Quadro de Quatro casas"(11). Essa técnica, ao combinar dois atributos relacionados às palavras ou às expressões evocadas, Que são a freqüência e a ordem em Que foram evocadas, possibilita a distribuição dos termos produzidos segundo a importância atribuída pelos sujeitos.

No alto e à esquerda (Quadrante superior esquerdo) ficam situados os termos verdadeiramente significativos para os sujeitos e Que constituem, provavelmente, o núcleo central da representação estudada. As palavras localizadas no Quadrante superior direito denomina-se primeira periferia; no inferior esquerdo, localizam-se os elementos de contraste; e aquelas localizadas no Quadrante inferior direito constituem a segunda periferia da representação(8,I I).

Cabe ressaltar que esta técnica integrada à informática torna-se um importante instrumento facilitador para a análise da estrutura e da organização de uma representação social ${ }^{(1)}$. Além disso, destaca-se Que os termos presentes no núcleo central possuem maior freqüência de evocações e menor rang Que, como já referido, refere-se à média das ordens médias de evocação. Entre os elementos periféricos ocorre o inverso, com palavras evocadas menos freqüentemente e com maior rang. Os de contraste e de primeira periferia apresentam variações nesses valores, com as palavras contidas no Quadrante inferior esQuerdo com uma freQüência de evocação inferior à freQüência média das palavras e um rang inferior ao rang médio, ao passo Que o Quadrante superior direito possui uma freqüência maior Que a freqüência média e um rang também maior.

Todos os preceitos necessários ao desenvolvimento de pesQuisas com seres humanos, de acordo com a resolução 196/96, foram obedecidos na realização deste estudo. Desta maneira, buscou-se a autorização institucional para o início da coleta de dados e adotouse, como imprescindível, a assinatura do Termo de Consentimento Livre e Esclarecido para cada sujeito, após as devidas e necessárias explicações acerca dos objetivos e dos aspectos metodológicos da peseuisa.

\section{RESULTADOS E DISCUSSÃO}

Nesta sessão do trabalho são apresentados os Quadros de Quatro casas construídos pelo software Evoc 2000 a partir dos termos indutores "autonomia profissional" e "enfermagem", evidenciando, desta maneira, os possíveis elementos centrais, de contraste e periféricos da representação social de enfermeiros acerca da temática presente no objeto de estudo.

Em relação ao corpus formado pelas evocações de todos os sujeitos ao termo "autonomia profissional" foram evocadas 331 palavras, sendo 160 palavras diferentes e 171 palavras repetidas. A média das ordens médias de evocação, ou seja, o rang foi igual a 2,6, ao passo que a freqüência média ficou estabelecida em 9 e a mínima 5.

A figura I evidencia a seguinte distribuição das palavras: no Quadrante superior esquerdo, conhecimento, conquista e responsabilidade, sendo estes os possíveis elementos centrais da representação; no Quadrante inferior direito e, conseQüentemente, constituindo-se como os prováveis elementos periféricos da representação, estão as palavras independência financeira, limitada, pouca, reconhecimento e utopia; dentre os elementos de contraste destacam-se importante, liberdade e respeito (Quadrante inferior esquerdo) e nos da primeira periferia, difícil e não.

Com relação aos possíveis elementos do núcleo central é importante destacar que a palavra responsabilidade apresenta a maior freuüência de evocações, ao mesmo tempo em Que foi evocada mais prontamente. Assim, este termo foi citado, ao todo, 17 vezes, sendo 7 no primeiro lugar, 4 no segundo, 3 no terceiro, 2 no Quarto e 1 no Quinto. No Que tange às outras duas palavras, conhecimento possui a maior Quantidade de evocações (1 5 vezes), e conQuista, um rang menor $(2,30)$, o Que indica sua citação mais prontamente.

O possível elemento nuclear de autonomia apresenta componentes representacionais de atitudes favoráveis à mesma, consubstanciadas nas palavras responsabilidade e conQuista. Devese considerar Que o crescente aumento do espaço profissional do enfermeiro é representado como conseqüência da evolução histórica, teórica e social da profissão. No entanto, esta conQuista e este espaço são frágeis frente à política pública estabelecida ou aos perfis de atuação dos gestores nas respectivas esferas institucionais e governamentais ${ }^{(3)}$. Desta maneira, o termo responsabilidade sugere a consciência da necessidade de atenção Quanto aos posicionamentos políticos e à explicitação do saber/ fazer por parte dos enfermeiros em seu cotidiano, demonstrando a representação deste espaço e, portanto, a autonomia profissional como processo em curso e não completamente estabelecida.

Assim, o termo conQuista possui significado especial ao lado de responsabilidade reforçando a idéia de processo, bem como demonstrando a presença de atitudes favoráveis ou desfavoráveis ao estabelecimento e ao alcance da autonomia pelos enfermeiros. A construção da identidade profissional ${ }^{(12)}$, de um saber específico enQuanto exercício de poder nas relações sociais, profissionais e institucionais da enfermagem ${ }^{(13)}$, da abordagem holística e humana ao cliente como traço característico da profissão( ${ }^{(5)}$ e a consulta de enfermagem como tecnologia/espaço privilegiados de exercício do saber/fazer profissional ${ }^{(14)}$ traduzem meios concretos de conquista da autonomia pelos enfermeiros.

Neste processo de coneuista da autonomia, diversas dificuldades podem ser citadas, dentre as Quais destacamos a formação profissional não fomentadora de uma prática autônoma e a ausência 
Espaço autônomo e papel próprio: representações de enfermeiros no contexto do binômio saúde coletiva-hospital

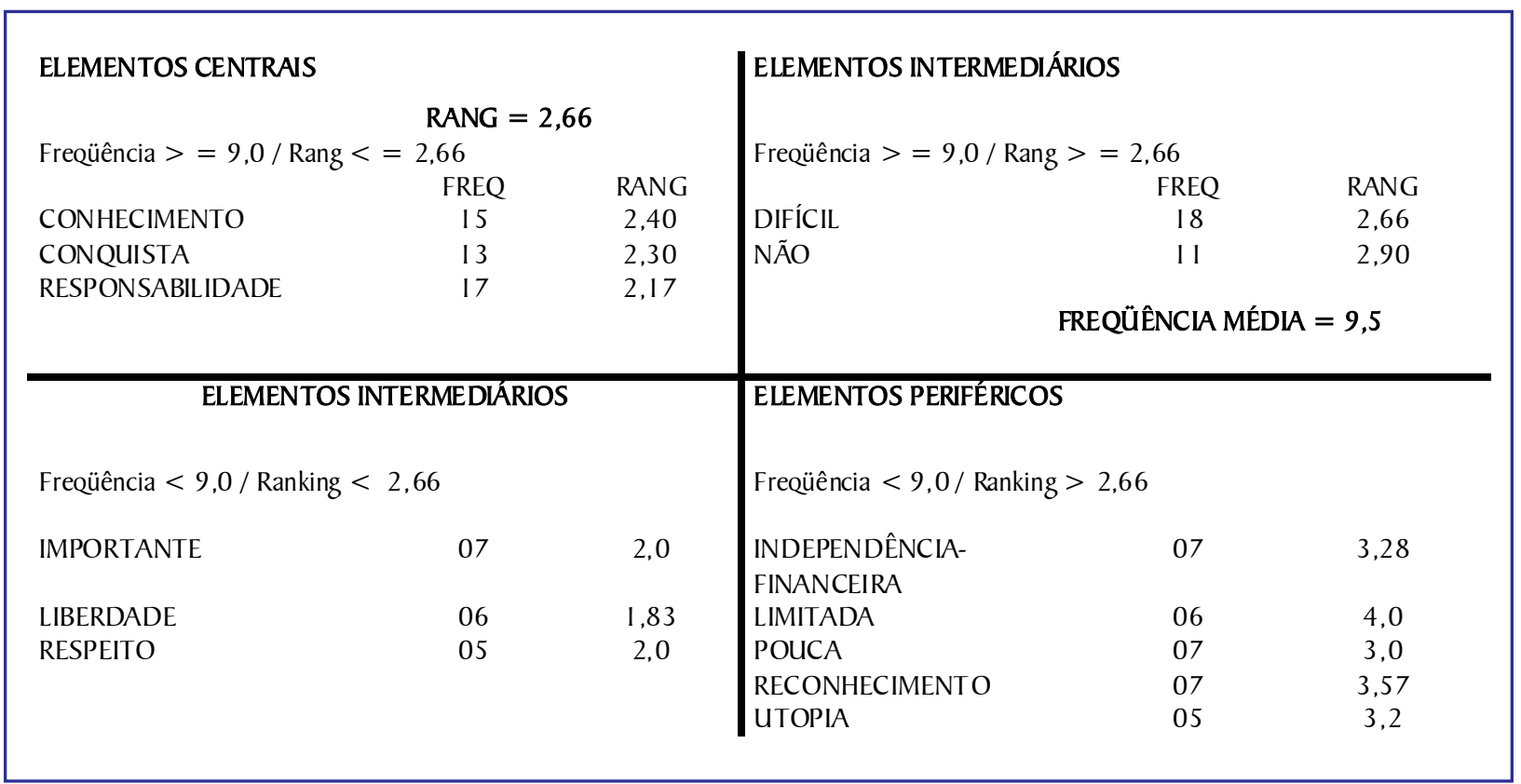

Figura 1. Quadro de euatro casas das evocações ao termo indutor autonomia profissional. Rio de janeiro, 2002.

de especificidade do papel próprio como geradora de limitações ao exercício de uma prática autônoma. Neste contexto, destaca-se Que a formação profissional do enfermeiro, em Que pese as iniciativas inovadoras de algumas universidades, ainda se sustenta nas ciências biomédicas e na disciplinarização dos alunos, tendendo a formar profissionais subordinados e, às vezes, sem capacidade de delimitação de um espaço de um saber/fazer próprio, apesar da evolução sócio-tecnológica da área e do crescimento da enfermagem tanto no âmbito teórico Quanto prático ${ }^{(4,15-16)}$.

Desta maneira, a formação deve expor os alunos a conteúdos e experiências de natureza diversas, de modo a desenvolver a capacidade do pensamento rápido, de resolução de situações críticas e de enfrentamento de confrontos. Simultaneamente, deve exercitar a auto-estima do profissional, a destreza manual e a decisão de prioridades, dentre outros fatores ${ }^{(17)}$.

Determinados autores $^{(12,16)}$ referem a existência de um fenômeno Que é a formação profissional insuficiente às demandas mercadológicas exigidas para o novo profissional. Muito mais do Que uma deficiência do aparelho formador, acredita-se em um descompasso entre os objetivos na Qual a formação se desenvolve e aqueles adotados pelo mercado para o desempenho dos novos profissionais.

Ou seja, a universidade forma e deseja profissionais com senso crítico desenvolvido e capacidade de refletir acerca da realidade, apresentando, como conseqüência, um fazer específico e contextualizado. O mercado, por sua vez, deseja um profissional Que tenha uma habilidade perfeita e rápida, não valorizando o pensar como prioridade de seu cotidiano, o Que significa uma tendência em absorver o tecnólogo ao invés do profissional de graduação plena.

Com relação à identidade profissional, percebe-se Que os enfermeiros não têm desempenhado seu papel próprio no cotidiano da profissão ${ }^{(18-19)}$. A construção deste papel possui relação com a constituição da identidade profissional, o Que significa a explicitação do Que é específico do enfermeiro, bem como do saber e do fazer Que caracterizam a enfermagem. Isso, contudo, não é uma negação à interdisciplinaridade, mas seu reforço, à medida Que, a partir do próprio, a enfermagem pode dar contribuições pertinentes e singulares à equipe de saúde e prestar uma assistência de Qualidade à sociedade ${ }^{(20)}$.

Assim, pode-se inferir que a responsabilidade permeia e perpassa toda essa dimensão representacional, sendo a base na Qual os sujeitos constroem o espaço profissional e a autonomia da enfermagem, possibilitando a conQuista e a manutenção do espaço de atuação dos profissionais e permitindo Que o processo de conquista se constitua de forma sólida, explicando a presença destacada do termo responsabilidade no núcleo central desta representação.

A palavra conhecimento pode estar significando, para os sujeitos, o conhecimento científico, possivelmente como conseQüência de um comportamento Que consideram relevante para o aperfeiçoamento profissional e para a coneuista de novos espaços de atuação. Desta maneira, o conhecimento científico e a construção e explicitação de um saber específico do enfermeiro constituem um dos alicerces da autonomia profissional.

Desta forma, a compreensão de autonomia em enfermagem a partir da constituição de um saber específico da profissão possui dois significados: a tentativa de delimitação de um núcleo essencial à mesma e a constituição, delimitação e especificação de um espaço próprio de poder. $\mathrm{O}$ primeiro daria sentido à prática profissional, ao menos em seus aspectos instrumentais, sendo estes definidos como fazeres úteis à prática de enfermagem e à necessidade dos clientes, embora não façam parte de sua constituição essencial ${ }^{(20)}$, o segundo, estabeleceria o espaço a partir do Qual as relações de poder vivenciadas com a equipe de saúde e com a sociedade seriam, não só exercidas, mas legitimadas.

Ao mesmo tempo, o conhecimento científico implica em uma autonomia de ação, especialmente na enfermagem, à medida Que 
este propicia a superação de uma prática tradicional baseada no empirismo e na repetição constante de procedimentos sem um suporte teórico suficiente e adequado aos desafios e dilemas enfrentados no cotidiano ${ }^{(21)}$. Logo, o conhecimento científico interfere na forma como a enfermagem se relaciona com as três populações Que convive diariamente, Quais sejam, a equipe de saúde, a clientela e a instituição empregadora.

Com relação à equipe de saúde, a atuação profissional do enfermeiro pautada no conhecimento científico permite a respeitabilidade mútua entre os profissionais e a confiabilidade da equipe no enfermeiro, gerando um trabalho interdisciplinar eficaz, ao mesmo tempo em Que compartilha responsabilidades, deveres e direitos. No que tange à clientela, o conhecimento científico torna-se importante no atendimento das necessidades e na resolução dos problemas da mesma, fazendo com Que se explicite a importância e a utilidade deste profissional dentro da equipe de saúde. Quanto à instituição, permite uma atuação profissional racional e eficaz, gerando resolutividade e retorno financeiro e social à organização.

Cabe destacar, ainda, Que estes prováveis elementos centrais da representação social de autonomia profissional possuem relação com comportamentos pessoais na construção do espaço autônomo de atuação dos profissionais. A importância destes tipos de comportamentos no estabelecimento da autonomia profissional já foi estudada por alguns autores ${ }^{(15-20)}$ ao considerarem Que esta não é somente reforçada ou construída por aspectos profissionais e técnicos, mas também por sentimentos e atitudes humanas como a solidariedade, a empatia, a ética e a responsabilidade, além da negociação política e da postura crítica.

Entre os elementos da primeira periferia da representação, um se destaca por reforçar o núcleo central, Qual seja, a palavra difícil
Que foi evocado 18 vezes e possui um rang de 2,66. Esta palavra foi citada prontamente seis vezes, sendo uma vez no segundo lugar e seis no terceiro.

Desta maneira, difícil pode estar refletindo a autonomia como processo, como ainda não estabelecida, o Que possui estreita ligação com conQuista. Simultaneamente, ressalta a importância da responsabilidade e do conhecimento científico como aspectos instrumentais e necessários ao estabelecimento de um campo profissional autônomo ${ }^{(20)}$.

O sistema periférico observado na figura I apresenta elementos Que possuem, ao mesmo tempo, menor Quantitativo de evocações e o rang em maior valor. Esses elementos possuem importância na forma como essa representação se relaciona com a realidade. Sob esse enfoque, torna-se relevante destacar independência financeira como sendo uma forma economicamente palpável de autonomia, tanto pela imagem elaborada de profissão liberal, Quanto pela Quantificação do trabalho e do saber do profissional.

Deve-se apontar a preocupação dos enfermeiros em demonstrar a importância sócio-econômica da profissão através da delimitação de ações socialmente importantes, necessárias e exclusivas. Neste aspecto, a prática profissional convive com tensões entre a constante especialização da profissão, gerando áreas específicas de saber/ fazer, normalmente com subsídios da ciência biomédica e, às vezes, com explícita intersecção com a prática médica. Outra Questão importante refere-se à determinação objetividade-subjetividade na prática cotidiana do enfermeiro e o valor social atribuído a essas dimensões $^{(22)}$.

Destaca-se, ainda, Que as palavras limitada, pouca e utopia observadas na periferia da representação parecem identificar a forma como a autonomia profissional é apreendida pelos sujeitos na interioridade do cotidiano profissional. Quando a autonomia do

\begin{tabular}{|c|c|c|c|c|c|}
\hline \multicolumn{3}{|c|}{ ELEMENTOS CENTRAIS } & \multicolumn{3}{|c|}{ ELEMENTOS PRIMEIRA PERIFERIA } \\
\hline FreQüência média & $\begin{array}{l}=2,9 \\
\text { FREQ }\end{array}$ & RANG & Freqüência média > & $\begin{array}{l}=2,9 \\
\text { FREQ }\end{array}$ & RANG \\
\hline $\begin{array}{l}\text { Amor } \\
\text { Dedicação }\end{array}$ & $\begin{array}{l}21 \\
39\end{array}$ & $\begin{array}{l}2,40 \\
2,80\end{array}$ & Trabalho & $\begin{array}{c}14 \\
\text { NCIA } 1\end{array}$ & $\begin{array}{r}3,30 \\
9,5\end{array}$ \\
\hline \multicolumn{3}{|c|}{ ELEMENTOS DE CONTRASTE } & \multicolumn{3}{|c|}{ ELEMENTOS SEGUNDA PERIFERIA } \\
\hline \multicolumn{3}{|c|}{ Freqüência média $<14$ / Rang $<2,90$} & \multicolumn{3}{|c|}{ Freqüência média $<14 /$ Rang $>2,90$} \\
\hline Carinho & 06 & 2,60 & Doação & 06 & 3,00 \\
\hline Compromisso & 08 & 2,00 & Luta & 06 & 3,50 \\
\hline Conhecimento & 06 & 2,60 & Pouco-reconhecida & 08 & 4,25 \\
\hline Cuidado & 13 & 2,38 & Prazer & 11 & 3,00 \\
\hline Profissionalismo & 06 & 2,50 & & & \\
\hline Realização & 13 & 2,46 & & & \\
\hline Respeito & 07 & 2,85 & & & \\
\hline Responsabilidade & 10 & 2,20 & & & \\
\hline Saúde & 06 & 2,33 & & & \\
\hline Vocacão & 09 & 1,77 & & & \\
\hline
\end{tabular}

Figura 2. Quadro de Quatro casas das evocações ao termo indutor enfermagem. Rio de Janeiro, 2002. 
Espaço autônomo e papel próprio: representações de enfermeiros no contexto do binômio saúde coletiva-hospital

enfermeiro é estabelecida como sinônimo ou restrita a procedimentos intervencionistas biomédicos tende a ocorrer uma sobreposição do instrumental ao Que é essencial da profissão, gerando uma representação de limitação profissional, se comparada à prática de outras profissões ou profissionais ${ }^{(15)}$.

Em relação ao corpus formado pelas evocações de todos os sujeitos ao termo enfermagem foram evocadas 450 palavras, sendo 200 palavras diferentes e 250 palavras repetidas. A média das ordens médias de evocação, ou seja, o rang foi igual a 2,90, ao passo Que a freqüência média ficou estabelecida em 14 e a mínima 6 .

Como demonstra o Quadro 2, os possíveis elementos centrais da representação de enfermagem dos entrevistados são amor e dedicação, presentes no Quadrante superior esquerdo e ambos com sentido ideológico muito forte. No sistema periférico, Quadrante inferior direito, aparecem doação, luta, poucoreconhecida e prazer. Na primeira periferia, isoladamente, aparece trabalho (Quadrante superior direito) e nos elementos de contraste (Quadrante inferior esQuerdo), observa-se carinho, compromisso, conhecimento, cuidado, profissionalismo, realização, respeito, responsabilidade, saúde e vocação.

Os componentes do núcleo central, amor e dedicação, comportam, para os profissionais, uma forte carga sentimental e ideológica Que possui sua raiz possivelmente na história da profissão. Nesse sentido, cabe destacar Que a enfermagem se estruturou em função do ser humano atendido e possui resQuícios históricos Que ainda ligam os profissionais à clientela a partir de sentimentos (amor) e atitudes (dedicação) Que possuem marcante influência de conceitos e comportamentos religiosos ${ }^{(1)}$.

O binômio amor-dedicação como núcleo estruturante da construção mental dos enfermeiros acerca da própria profissão tende a colocar a enfermagem em uma situação em Que dois posicionamentos são possíveis de serem concretizados. O primeiro refere-se à consubstanciação de uma prática dependente e abnegada, oriunda de princípios religiosos ou do recomendado para "a posição de enfermeira" Que constrói o seu saber/fazer enfatizando o empírico e a inter-relação em detrimento da ciência, da evolução tecnológica e da construção de um espaço autônomo de atuação ${ }^{(20)}$.

Esta atitude profissional possui raiz também em uma compreensão ideológica da realidade em Que se prioriza o crescimento interior e a possibilidade de ajuda ao ser humano nas diversas etapas Que caracterizam a sua existência, especialmente naQuelas em que a dor, o sofrimento e a morte se fazem presentes. Neste contexto, acredita-se no crescimento mútuo entre o profissional e a clientela, normalmente direcionado para sentimentos de resignação e de aceitação do vivido, característicos da religiosidade brasileira em função da associação do catolicismo, protestantismo e espiritismo ${ }^{(23)}$.

A segunda refere-se à adoção do binômio no âmbito da prática profissional em um contexto de novas visões ecológicas, teológicas

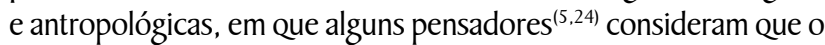
amor apresenta-se como o elemento essencial na relação humana, ao mesmo tempo em Que possui a capacidade de transformação de situações vivenciadas e experienciadas pelos sujeitos. Nesta premissa, o profissional não faria pelo cliente ou para ele, mas desenvolveria uma atitude empática e de compaixão, colocando-se ao seu lado e permitindo a sua construção enQuanto sujeito de seu processo saúde-doença.

Desta maneira, pode-se apontar o amor como fonte de cura no cotidiano das instituições de saúde ${ }^{(25)}$. Esta referência ao amor significa a capacidade de relacionamento humano que não "coisifica", isto é, não transforma o ser relacionado em objeto, mas o impele a ser sujeito e a ter direitos de expressar-se e movimentar-se de acordo com sua visão de mundo. $\mathrm{O}$ amor, neste sentido, não se refere ao sentimentalismo, mas à capacidade de empatia permeada pela ética de respeito ao ser humano. Neste sentido, a empatia é um dos elementos da cura e de ajuda no processo saúde-doença, especialmente através da comunicação sutil, Que envolve intercâmbio não-verbal, crenças e atitudes ${ }^{(20)}$.

Esta última tendência tende a incluir a tecnologia desenvolvida em saúde, embora redimensione a sua importância e o seu papel no atendimento à clientela. Transpondo esses aspectos para a prática de enfermagem, ressalta-se Que esta profissão apresenta duas dimensões do cuidar, Que não são excludentes, mas complementares no exercício diário, Quais sejam, a dimensão afetiva/expressiva e a dimensão técnica/instrumental ${ }^{(24)}$. Desta forma, a capacidade afetiva, emocional e empática encontra também uma forma de expressão nos cuidados necessários no cotidiano das instituições de saúde e Que são importantes à promoção da saúde, à prevenção das doenças ou, ainda, ao restabelecimento da saúde dos indivíduos.

Importa destacar Que não existe um posicionamento certo ou errado, mas aquele que atende, de uma forma mais adequada, às demandas presentes na sociedade, na clientela e nos profissionais em um determinado momento histórico e em um contexto social. Destaca-se, contudo, Que este último apresenta-se mais amplo e com uma capacidade de unir várias dimensões, como a espiritual, a religiosa, a humanística e a solidária.

O sistema periférico apresenta as formas de inter-relação entre o núcleo central e a prática, aparecendo doação como forma concreta da dedicação e do amor, ao mesmo tempo em Que o prazer é referido no âmbito da concretização da profissão. Percebe-se, neste contexto, a presença de dimensões representacionais ligadas novamente à atitude (doação) e a sentimentos (prazer).

Neste sentido, a estrutura representacional da enfermagem parece estar intimamente relacionada ao ser profissional e às suas disposições internas. Este fato, por um lado, oferece uma beleza própria à profissão, mas, por outro, dificulta a formação de contornos considerados científicos pela atualidade, bem como a adoção de padrões de pensar/fazer tidos como relevantes às profissões da área da saúde no mundo gobalizado e hodierno ${ }^{(12,20)}$.

Nesta segunda periferia, parece existir o cruzamento de uma dimensão social Que, possivelmente, possui origem na religiosidade característica da história da enfermagem e da abnegação necessária para a concretização deste perfil (doação), com um sentimento individual (prazer), conseqüência de uma relação pessoal do profissional com a enfermagem e a clientela e como esta relação é apreendida pelo self do enfermeiro. Embora sejam dimensões diferenciadas, ambas se entrecruzam tornando-se complementares na cartografia mental desses sujeitos em sua apreensão acerca da atividade laborativa Que exercem.

Ao mesmo tempo, luta parece demonstrar o cotidiano profissional em sua dimensão de equipe e institucional, demonstrando como a profissão acontece no dia a dia e as situações Que são enfrentadas para Que isto ocorra. Alguns estudos ${ }^{(20,26)}$ apontam o conflito 
cotidiano necessário à conQuista do espaço profissional, além das Questões de poder ligadas aos aspectos técnicos, hierárQuicos e políticos.

O termo pouco reconhecida abrange a construção mental dos profissionais acerca da relação da profissão com o meio no Qual está inserida, explicitando o modo como os enfermeiros captam a reação deste fator externo, Que se refere tanto à população, Quanto à equipe de saúde e à instituição em Que trabalham. Neste meio também estão localizadas as representações sociais acerca da profissão, o valor social Que lhe é atribuído e como isto se reveste de benefícios direto ao profissional, Quer em Questões concretas (salário, acomodações institucionais e bens de consumo, por exemplo) ou simbólicas (prestígio, reconhecimento e admiração, dentre outras).

Os elementos de contraste apresentam a tensão estabelecida no bojo da representação em Que vocação se estabelece como um outro extremo de profissionalismo. Este nuance representacional parece demonstrar a dualidade vivida no cotidiano profissional, em Que o empírico e o científico e o inter-relacional e o tecnológico se misturam e se substituem.

Outro aspecto interessante a ser destacado é a presença do léxico cuidado, Que tem sido considerado como o objeto de trabalho do enfermeiro, bem como sua essência e sua manifestação mais característica. Se, por um lado, esta palavra possui maior freeüência entre os elementos presentes na zona de contraste (13), chama a atenção a sua não-evocação entre os primeiros lugares (rang 2,38), o que parece indicar que a importância dada a este conceito pode se referir mais a uma discussão acadêmica (Que o pensa) do Que aos profissionais (Que o executam), embora estes tenham absorvido, em grau variável, a centralidade do cuidar/cuidado no âmbito profissional.

\section{CONSIDERAÇÕES FINAIS}

Considera-se Que as estruturas representacionais expostas demonstram um processo de coneuista da autonomia profissional, fenômeno este Que parece estar em curso. Este espaço autônomo não se encontra plenamente estabelecido, o Que justifica as tensões encontradas entre os diversos elementos da representação social.

Um traço marcante e transversal a ambas estruturas foram as Questões atitudinais dos enfermeiros como centrais à construção mental dos sujeitos do estudo. Isto pode estar relacionado à não consolidação do espaço autônomo de atuação, bem como à não explicitação do Que é essencial à representação, colocando-se a base de sustentação mais no perfil profissional do Que na enfermagem como área de saber e campo de prática.

Os dados demonstram o momento de transição vivenciado pela enfermagem, em Que ainda se observa a presença de dimensões Que foram hegemônicas em um determinado momento histórico da profissão, como a religiosidade, e aponta outras oriundas da cientificidade atual, como o conhecimento e o profissionalismo. Desta maneira, os enfermeiros vivenciam o já e o ainda não da autonomia em seus cotidianos, com avanços em áreas específicas da enfermagem e estagnação em outras.

\section{REFERÊNCIAS}

I. Collière MF. Promover a Vida. Lisboa (POR): Sindicado dos Enfermeiros Portugueses; 1989.

2. Waldow VR. Cuidado Humano: O Resgate Necessário. Porto Alegre (RS): Sagra Luzzato; 1998.

3. Almeida MCP, Mishima SM, Silva EM, Mello DF. O trabalho de enfermagem e sua articulação com o processo de trabalho em saúde coletiva-rede básica de saúde. In: Almeida MCP, Rocha SMM, organizadores. O trabalho de enfermagem. São Paulo (SP): Cortez; 1997. p. 61-1 12.

4. Lunardi VL. A sanção normalizadora e o exame: fios visíveis/ invisíveis na docilização. In: Waldow VR, Lopes MJM, Meyer $\mathrm{DE}$, organizadoras. Maneira de cuidar, maneira de ensinar - A enfermagem entre a escola e a prática profissional. Porto Alegre (RS): Artes Médica; 1995. p. 79- 108.

5. Capra F. O ponto de mutação. São Paulo (SP): Editora Cultrix; 1982.

6. Moscovici S. A representação social da psicanálise. Rio de Janeiro (RI): Zahar Editores; 1978.

7. Abric IC. A abordagem estrutural das representações sociais In: Moreira ASP, Oliveira DC, organizadoras. Estudos interdiciplinares em representação social. Goiânia (GO): AB Editora; 2000. p. 27-38

8. Sá CP. Núcleo central das representações sociais. Petrópolis (RJ): Vozes; 1996.

9. Oliveira DC. A Promoção da saúde da criança: análise das práticas cotidianas através do estudo das representações sociais [tese]. São Paulo (SP): Faculdade de Saúde Pública,
Universidade de São Paulo; 1996.

10. Abric IC. Práticas Sociales y Representaciones. Cuidad de México (MEX): Ediciones Coyoacán; 2001.

11. Vergès P. Approche du noyau central: proprietés Quantitatives et estructurales. In: Guimelli C. Structures et transformation des representations sociales. Paris (FRA): Delachaux et Niestlé; 1994. p. 233-53.

12. Guitton B, Figueiredo N, Porto I. A passagem pelos espelhos: a construção da identidade profissional do enfermeiro. Niterói (RI): Intertexto; 2002.

13. Foucault M. Microfísica do poder. Rio de Janeiro (RJ): Edições Graal; 1988.

14. Vanzin AS, Nery MES. Consulta de enfermagem: uma necessidade social? Porto Alegre (RS): RM\&L; 1996.

15. Villa EA, Cadete MMM. A cultura institucional como determinante da prática educacional do enfermeiro. Texto Contexto: Enferm 2000; 9(3): 115-32.

16. Loureiro M, Vaz MRC. Refletindo sobre o "Ensinar e Aprender" para a autonomia e a transformação da realidade. Texto Contexto: Enferm 2000; 9(3): 230-48.

17. Rodrigues MSP, Leitão GCM. Estágio curricular supervisionado com ênfase no desenvolvimento da autonomia e da responsabilidade. Texto Contexto: Enferm 2000; 9(3): 216-29.

18. Lunardi Filho WD. O mito da subalternidade do trabalho da enfermagem à medicina. Pelotas (RS): Ed. Universitária-UFPel/ UFSC; 2000. 
Espaço autônomo e papel próprio: representações de enfermeiros no contexto do binômio saúde coletiva-hospital

19. Svaldi JSD, Lunardi Filho WD. Poder e gerenciamento na enfermagem. Texto Contexto: Enferm 2000; 9(3): 22-4I.

20. Gomes AMT. A autonomia profissional da enfermagem em Saúde Pública: um estudo de representações sociais [dissertação]. Rio de Janeiro (R]): Faculdade de Enfermagem, Universidade do Estado do Rio de Janeiro; 2002.

21. Almeida MCP, Rocha SMM. Considerações sobre a enfermagem enQuanto trabalho. In: Almeida MCP, Rocha SMM, organizadoras. O trabalho de enfermagem. São Paulo (SP): Cortez; 1997. p. 15-26.

22. Figueiredo NMA. A mais bela das artes... O pensar e o fazer da enfermagem: bases teóricas e práticas para uma teoria do cuidado/conforto [tese]. Rio de Janeiro (RI): Faculdade de
Enfermagem, Universidade do Rio de Janeiro; 1997.

23. Gomes AMT. Silêncio, silenciamento e ocultamento na terapia antiretroviral: desvelando o discurso dos cuidadores de crianças [tese]. Rio de Janeiro (RI): Escola de Enfermagem Anna Nery, Universidade Federal do Rio de Janeiro; 2005.

24. Boff L. Saber cuidar: ética do humano, compaixão pela terra. Petrópolis (RJ): Vozes; 1999.

25. Siegel B. Amor, agente da cura. In: Carlson R, Shield B, organizadores. Curar, curar-se. São Paulo (SP): Ed, Cultrix; 1989. p. 19-25.

26. Gomes AMT, Oliveira DC. A representação social da autonomia profissional do enfermeiro na saúde pública. Rev Bras Enferm 2005; 58(4): 393-8. 